\title{
Surface texture after finishing turning of AISI 630 martensitic steel
}

\author{
Struktura geometryczna powierzchni po toczeniu \\ wykończeniowym stali martenzytycznej AISI 630
}

\section{KAMIL LEKSYCKI EUGENE FELDSHTEIN *}

The surface texture of martensitic AISI 630 steel after the finishing turning is described. The tests were carried out under dry and cooling conditions. Experiments were carried out under variable cutting speeds and feeds and under a constant depth of cut. The Parameter Space Investigation (PSI) method was used that allows research with minimal experience point quantity. It was found that turning with cooling conditions reduce both $R a$ and $R q$ values and intensities of cutting speed and feed rate influence as compared out under dry conditions. The use of low feed rate values has a positive effect of the $R a$ and $R q$ parameters.

KEYWORDS: surface texture, finish turning, martensitic steel AISI 630

The progress of medicine is to a large extent based on the use of increasingly better materials in medical devices. Currently, a number of biomedical materials are used [1].

Due to the favorable mechanical and functional properties, the most commonly used biomedical materials include, among others, $316 \mathrm{~L}$ stainless steel and Ti-6Al-4V alloys, Co-Cr-Mo, Ni-Ti [2]. The AISI 630 stainless steel is more and more popular in the medical industry because it has many advantages [3, 4].

Martensitic, chromium-nickel aging stainless steel AISI $630(17 \mathrm{Cr}-4 \mathrm{Ni})$ is characterized by high strength, hardness and ductility and excellent corrosion resistance [5]. This material also has a low thermal conductivity, which reduces machinability and affects the quality of the surface [6].

The surface quality largely determines the usable properties of the workpieces, including tribological properties, fatigue strength and corrosion resistance [7]. Surface roughness is a popular indicator of element quality assessment, used as a general technical requirement of the product [8]. In the turning process, parameters such as cutting speed, feed, depth of cut or corner radius of the tool affect the quality of the surface. In addition, high temperatures occur during turning in the cutting zone, which contributes to increased surface roughness $[9,11,12]$.

In [10], the quality of AISI 630 steel surface obtained in a

\footnotetext{
* Mgr inż. Kamil Leksycki (k.leksycki@ibem.uz.zgora.pl), prof. dr hab. inż. Eugene Feldshtein (e.feldshtein@ibem.uz.zgora.pl) - Uniwersytet Zielonogórski
}

finishing turning process carried out with cooling (water with oil emulsion) was evaluated. At an average cutting speed and low feed, a low surface roughness was achieved, while a high roughness was obtained at a very low cutting speed and high feed. In addition, it has been proven that the cutting depth changed simultaneously with the cutting speed or feed does not affect the surface roughness. It has been found that turning with a low cutting speed reduces surface roughness.

In [13], the mechanism of tool wear in the AISI 630 finishing turning process was investigated. Small surface roughness was obtained with medium cutting speed and low feed. On the other hand, high roughness was obtained when turning with high cutting speed and low feed.

The research was aimed at determining the impact of cutting speed and feed on selected surface roughness indices obtained during finishing of AISI 630 stainless steel, dry and with cooling.

\section{Implementation of research}

The experiment uses the Parameter Space Investigation (PSI) method, which allows you to plan tests while minimizing the number of test points [14]. Normalized coordinates of the test points are presented in [15].

The research was carried out on a CTX 510 CNC lathe with the Sinumerik $840 \mathrm{D}$ control by DMG MORI. A turning tool with a CoroTurn SDJCR 2525M 11 holder and a CoroTurn DCMX 11 T3 04-WM 1115 insert was used. The total size of the blade did not exceed $0.2 \div 0.3 \mathrm{~mm}$, which corresponds to the finishing conditions; in order to eliminate its impact, the order of tests was randomized.

Cutting speeds in the range of $V_{c}=150 \div 500 \mathrm{~m} / \mathrm{min}$, feeds in the range $f=0.05 \div 0.4 \mathrm{~mm} / \mathrm{rev}$ at constant cutting depth $a_{p}=0.5 \mathrm{~mm}$, which corresponds to the finishing conditions.

The finishing treatment was carried out without the use of a cooling-lubricating agent (dry) and using an aqueous emulsion based on Castrol Alusol SL 51 XBB emulsifying oil with a working concentration of $7 \%$.

Martensitic aging stainless steel AISI 630 with chemical composition given in [16] was machined.

The geometrical structure of the AISI 630 steel surface after finishing turning was tested with the TR-200 device. 


\section{Test conditions}

The results of measurements obtained at individual study points were subjected to statistical analysis in the Statistics 13.0 program, thanks to which a regression equation was obtained. Graphs of changes in the surface roughness parameter $R a$ depending on the cutting speed and feed rate in the dry and cooled machining conditions are shown in fig. 1 , while the surface roughness parameter $R q$ changes - in fig. 2 .

It is worth noting that the Ra parameter in the concept of mathematical statistics is the average of a random sample (mathematical expectation), while the $R q$ parameter equals standard deviation.

a)

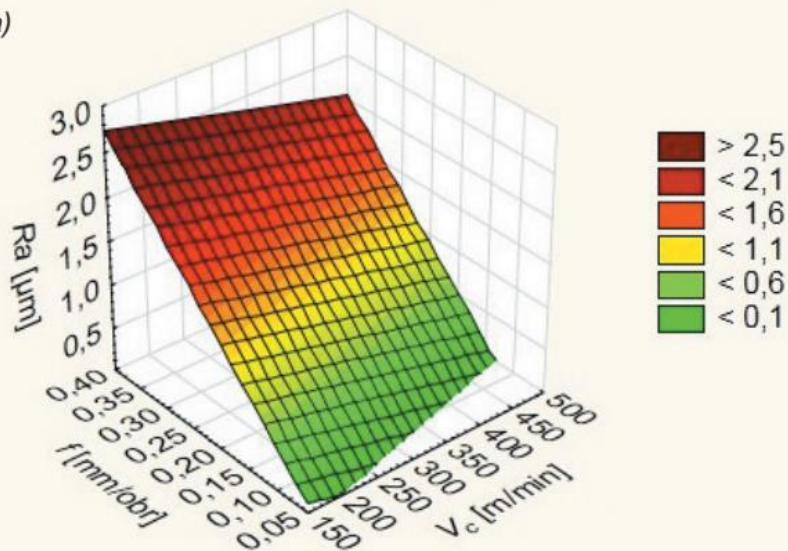

b)

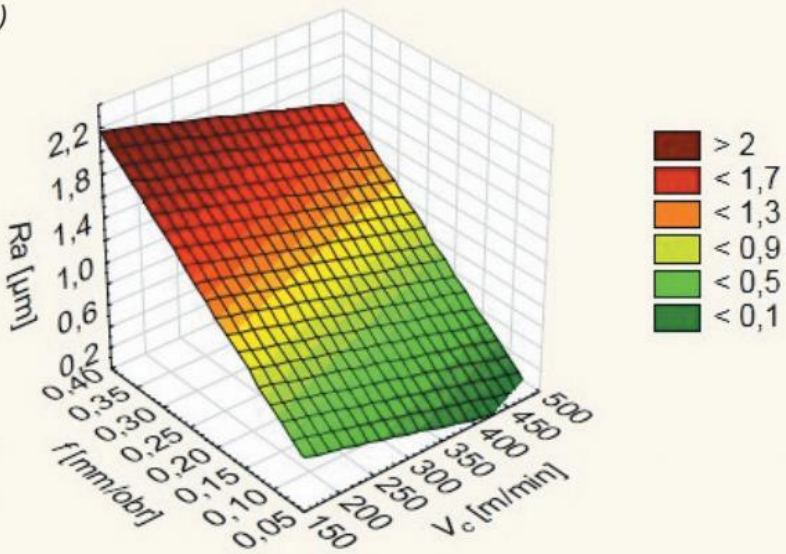

Fig. 1. Changes in the surface roughness parameter $R a$ depending on the cutting speed $V_{c}$ and feed $f$ at: a) dry machining, $b$ ) machining with cooling

For calculations of the surface roughness parameter $R a$, regression equations were obtained: - dry:

$$
R a=0,0266-0,002 V_{c}+7,5613 f ; R^{2}=0,87
$$

- with cooling:

$$
R a=0,5265-0,018 V_{c}+4,8077 f, R^{2}=0,90
$$

where: $V_{c}$ - cutting speed in $\mathrm{m} / \mathrm{min} ; f$ - feed in $\mathrm{mm} / \mathrm{rev}$.

Based on the obtained results, it was found that during cooling with cooling, both $R a$ and $R q$ values as well as the intensity of the cutting speed and feed rate decreases as compared to the dry machining. In dry and cooled turning, it was noticed that the lower the feed values, the lower the surface roughness indicators tested. However, the influence of the cutting speed on $R a$ and $R q$ parameters was insignificant; more favorable results were obtained at high speeds.
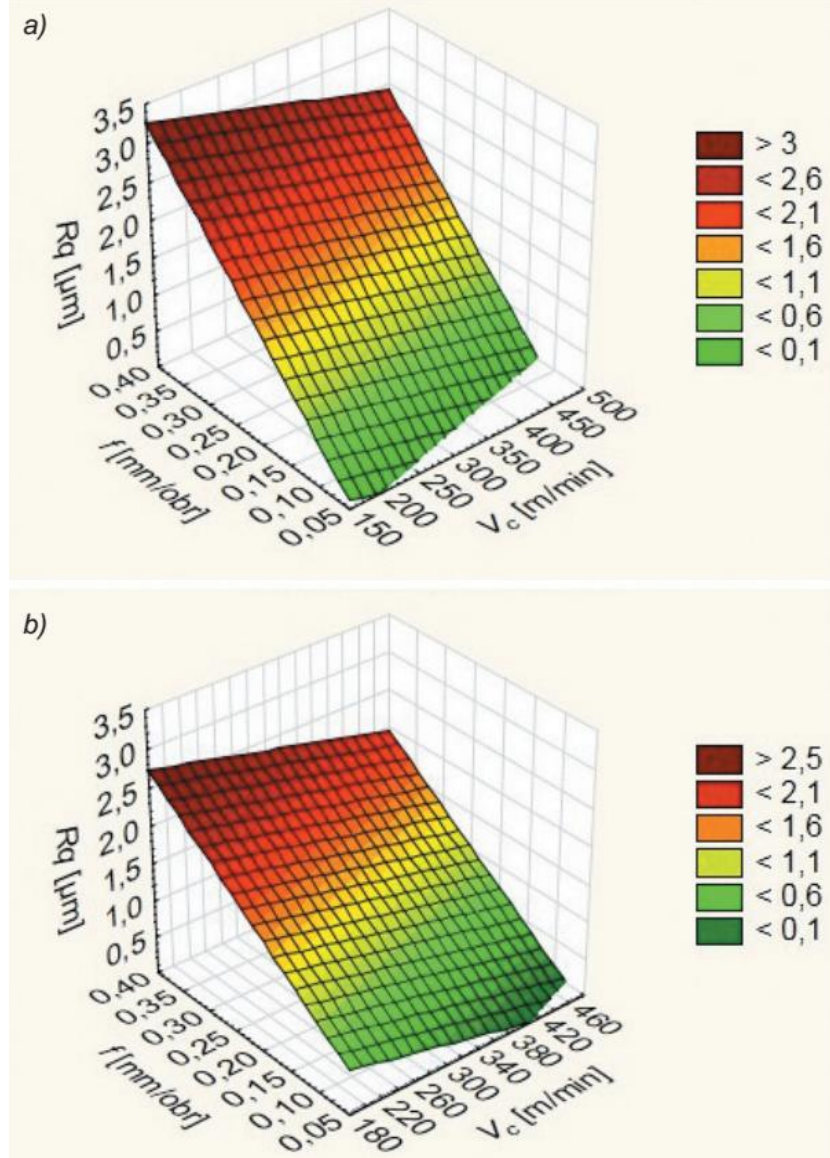

Fig. 2. Changes of the surface roughness parameter $R q$ depending on the cutting speed $V_{c}$ and feed $f$ at: a) dry machining, b) machining with cooling

For the calculation of the surface roughness parameter $\mathrm{Rq}$, the regression equations were obtained: - dry:

$$
R q=0,0196-0,0024 V_{c}+8,9974 f, R^{2}=0,89
$$

- with cooling:

$$
R q=0,7703-0,0026 V_{\mathrm{c}}+6,1135 f ; R^{2}=0,93
$$

Roughness parameters were also analyzed at individual test points according to the PSI method.

Fig. 3 shows average percentage changes of roughness parameters $R a$ and $R q$ of AISI 630 stainless steel surface after finishing turning in dry conditions and with cooling depending on variable cutting speed and feed parameters.

The use of cooling at medium and high feeds resulted in a decrease in the value of the tested surface roughness parameters in the range from $3 \%$ to $25 \%$. At low feeds, the selected roughness parameters increased from $38 \%$ to $140 \%$. The influence of cutting speed on $R a$ and $R q$ parameters was negligible.
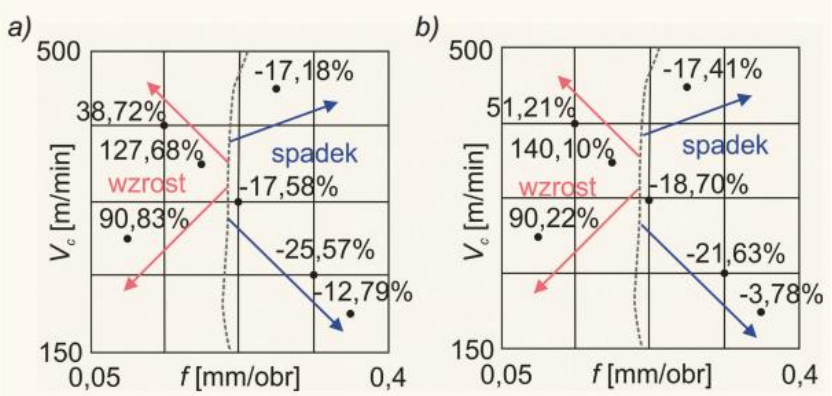

Fig. 3. Average percentage reduction of selected roughness parameters in seven test points according to the PSI method after turning with cooling compared to dry machining: a) Ra parameter, b) Rq parameter 
Fig. 4 presents profiles of surface roughness at points where large and small values of surface roughness parameters were observed.
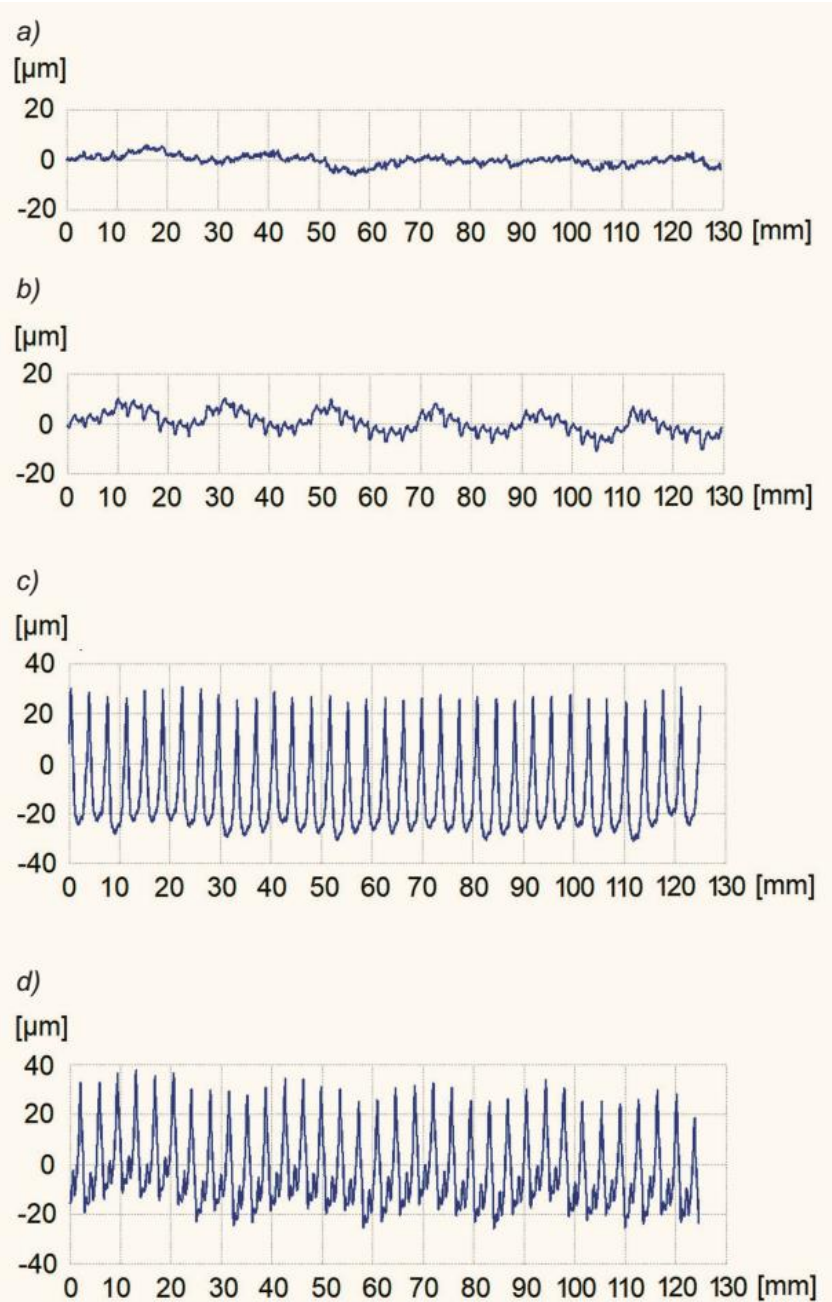

Fig. 4. Roughness profiles in selected treatment conditions: a) dry with $V_{\mathrm{c}}=281.25 \mathrm{~m} / \mathrm{min}$ and $\left.f=0.093 \mathrm{~mm} / \mathrm{rev}, b\right)$ with cooling with $V_{\mathrm{c}}=281.25 \mathrm{~m} / \mathrm{min}$ and $\left.f=0.093 \mathrm{~mm} / \mathrm{rev}, c\right)$ dry with $V_{\mathrm{c}}=193.75$ $\mathrm{m} / \mathrm{min}$ and $f=0.356 \mathrm{~mm} / \mathrm{rev}, d$ ) with cooling with $V_{\mathrm{c}}=193.75 \mathrm{~m} / \mathrm{min}$ and $f=0.356 \mathrm{~mm} / \mathrm{rev}$

Noteworthy are the parameters: $V_{\mathrm{c}}=281.25 \mathrm{~m} / \mathrm{min}$ and $f$ $=0.093 \mathrm{~mm} / \mathrm{rev}$, at which small values of $R a$ and $R q$ were obtained, while rolling with $V_{\mathrm{c}}=193.75 \mathrm{~m} / \mathrm{min}$ and $f=0.356$ $\mathrm{mm} / \mathrm{rev}$, large yields were obtained. $R a$ and $R q$ values.

Low feed at low cutting speeds reduces the roughness parameters tested. However, with high feed and medium cutting speed, large $R a$ and $R q$ parameters were obtained.

\section{Conclusions}

Based on the results of the research, the following conclusions were made:

- when turning with cooling, both $R a$ and $R q$ values as well as the intensity of the cutting speed and feed rate decreases as compared to the dry machining,

- the use of low feeds has a positive effect on the $R a$ and $R q$ parameters,

- cutting speed slightly affects the $R a$ and $R q$ parameters,

- cooling with medium and high feeds reduces $R a$ and $R q$ by $3 \%$ to $25 \%$,

- low-feed machining increases the $R a$ and $R q$ parameters by $38 \%$ to $140 \%$.

\section{REFERENCES}

1. Dobrzański L.A. „Podstawy kształtowania struktury i właściwości materiałów metalowych”. Gliwice: Wyd. Politechniki Śląskiej, 2007.

2. Ramsden J.J., Allen D.M., Stephenson D.J., Alcock J.R., Peggs G.N., Fuller G., Goch G. „The design and manufacture of biomedical surfaces". Annals of the CIRP. 56 (2007): pp. 687-711.

3. Ahlhelm M., Günther P., Scheithauer U., Schwarzer E., Günther A., Slawik T., Moritz T., Michaelis A. „Innovative and novel manufacturing methods of ceramics and metal-ceramic composites for biomedical applications". Journal of the European Ceramic Society. 36 (2016): pp. 2883-2888.

4. Liu G., Huang C., Zou B., Wang X., Liu Z. „Surface integrity and fatigue performance of $17-4 \mathrm{PH}$ stainless steel after cut-ting operations". Surface \& Coatings Technology. 307 (2016): pp. 182189.

5. Liu R.L., Yan M.F. „The microstructure and properties of $17-4 \mathrm{PH}$ martensitic precipitation hardening stainless steel modified by plasma nitrocarburizing". Surface \& Coatings Technology. 204 (2010): pp. 2251-2256.

6. Liu G., Zou B., Huang C., Wang X., Wang J., Liu Z. „Tool damage and its effect on the machined surface roughness in highspeed face milling the 17-4PH stain-less steel". Int. J. Adv. Manuf. Technol. 83 (2016): pp. 257-264.

7. Yanga J., Wanga X., Kang M. „Finite element simulation of surface roughness in diamond turning of spherical surfaces. Journal of Manufacturing Processes. 31 (2018): pp. 768-775.

8. Benardos P.G., Vosniakos G.C. „Predicting surface roughness in machining: a review". Int J Mach Tools Manuf. 43 (2003): pp. 833-844.

9. Patole P.B., Kulkarni V.V. „Optimization of Process Parameters based on Surface Roughness and Cutting Force in MQL Turning of AISI 4340 using Nano Fluid". Materials Today: Proceedings. 5 (2018): pp. 104-112.

10. Kiran P.C., Clement S. „Surface quality investigation of turbine blade steels for turning proces". Measurement. 46 (2013): pp. 1875-1895.

11. Zawada-Tomkiewicz A. „Analiza układu obróbkowego z wykorzystaniem informacji zawartych w powierzchni obrobionej". Mechanik. 8-9 (2013): pp. 119-126.

12. Zawada-Tomkiewicz A., Storch B. „Analiza struktury geometrycznej powierzchni $z$ wykorzystaniem krzywej udziału materiału". Mechanik. 11 (2016): pp. 1728-1729.

13. Zou B., Zhou H., Huang C., Xu K.,Wang J. „Tool damage and machined-surface quality using hot-pressed sintering $\mathrm{Ti}(\mathrm{C} 7 \mathrm{~N} 3) / \mathrm{WC} / \mathrm{TaC}$ cermet cutting inserts for high-speed turning stainless steels". Int. J. Adv. Manuf. Technol. 79 (2015): pp. 197210.

14. Statnikov R.B., Matusov J.B. „Multicriteria Analysis in Engineering". Springer, 2002.

15. Maruda R.W., Krolczyk G.M., Niesłony P., Krolczyk J.B., Legutko S. "Chip formation zone analysis during the turning of austenitic stainless steel 316L under MQCL cooling conditio". Procedia Engineering. 149 (2016 ): pp. 297-304.

16. www.matweb.com (26.03.2018)..

Translation of scientific articles, their computer composition and publishing them on the website www.mechanik.media.pl by original articles in Polish is a task financed from the funds of the Ministry of Science and Higher Education designated for dissemination of science.

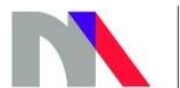

Ministry of Science and Higher Education

Republic of Poland 